\title{
REGENERATION OF FERTILE PLANTS FROM SUNFLOWER (Helianthus annuus L.) - IMMATURE EMBRYO
}

\author{
Dagustu, N. , Sincik, M., Bayram, G., Bayraktaroglu, M.
}

Uludag University, Faculty of Agriculture, Department of Field Crops, 16059 Görükle Bursa, Turkey

Received: March 18, 2010

Accepted: May 28, 2010

\section{SUMMARY}

Immature embryos from 15 sunflower genotypes (five restorers, five cytoplasmic male steriles, and five maintainers) were studied with the aim to shorten the seed to seed cycle, because seed maturation in sunflower takes 50$60 \%$ of the life cycle duration (120-150 days). This technique allows the production of fertile plants from immature embryos by reducing the breeding cycle. Ten days after pollination immature embryos were dissected from seeds grown in field plants (SGFP) and were transferred to MS medium allowing shoot and root development for 5-10 days. Young plantlets were transferred to soil, developed to maturity, and were then self pollinated and set seed. The first cycle of immature embryo-raised plants (ERP) was obtained. When these plants were at the flowering stage, 10-day-old embryos were dissected and the $2^{\text {nd }}$ cycle of ERP was obtained. The plants at the flowering stage for obtaining the $3^{\text {rd }}$ cycle are in the growth chamber at the moment.

The majority of cultured embryos developed into vigorous plantlets with 3-6 leaves. Out of the 1710 immature embryos, the average response of the explants was $93.1 \%$ (1591) showing morphogenesis with a minimum of 42.5 [N Record 109/Sanay 1-2(N)] and a maximum of 100\% [(PR6404 (cms), Narmo Sanay 6-1 (cms), RIM 1-5 (cms), BGC0565 (N), N Record 109/Iscra (N), RHA 04, RHA 06, RHA 10, RHA 14, RHA 15]. Seventy percent of the developed plantlets had vigorous roots. They were transplanted into containers with a 1:1:2 peat: perlite: soil mixture (v/v) at $24 \pm 2^{\circ} \mathrm{C}$ in $16 \mathrm{~h} / 8 \mathrm{~h}$ (light/dark) in a growth chamber. Only $67.3 \%$ of them were grown to maturity, either self-pollinated or pollinated with maintainers and set seeds. The overall result was an average of 40-50 regenerated and matured plants per 100 immature zygotic embryos.

Key words: sunflower, immature embryo, fertile plant regeneration

* Corresponding author: Phone: +90 224 2941518; Fax: +90 224 2941402;

e-mail: ndagustu@uludag.edu.tr 


\section{INTRODUCTION}

Sunflower (Helianthus annuus L.) is one of the most important oil seed crops in both Turkey and the world. The development of hybrids with good agronomic performances is an important target in sunflower breeding programs. Sunflower is a highly cross-pollinated crop and any breeding program on this crop involves several breeding cycles. Obtaining homozygous lines for hybrid seed production in a short period of time is of great importance for commercial hybrid production. In the field, sunflower plants are grown from seeds during the growing season. Therefore, only one generation a year is used in the breeding program. In the Marmara Region in Turkey, sunflower seeds are sown from April to the beginning of May and the plants are generally harvested in early September. The seed to seed cycle takes about 120-150 days to complete to maturity phase for reseeding for the next generation. For that reason, a second year is necessary to obtain seeds under natural field conditions in the region. The length of one cycle is quite often a limiting factor in achieving a breeding aim in a reasonable amount of time. Sunflower breeders require a minimum of six generations with conventional methods for obtaining homozygous lines if the population is derived from a cross between two inbred lines (Hu et al., 2008). It is also known that sunflower seeds keep their germination capacity for about six days after pollination and become dormant 16 days after pollination (Maiti et al., 2006) and that seed maturation in sunflower takes $50-60 \%$ of the life cycle duration (Serieys, 1992). Consequently, reducing the duration of one cycle should be of great importance for a breeder aiming to obtain seed propagated cultivars or lines and new sources of maintainers $(\mathrm{N})$, restorers $(\mathrm{R})$ and cytoplasmically male sterile $(\mathrm{cms})$ lines.

The application of new technologies such as in vitro tissue culture methods (anther culture, microspore culture, ovule culture, immature embryo culture from interspecific hybridization, etc.) accelerates the breeding process in sunflower. The sunflower embryo culture system was first developed for interspecific hybridization by Chandler and Beard (1983). Embryo culture has been used successfully by plant breeders in solving the problems of seed set, seed dormancy, slow seed germination, inducing embryo growth in the absence of symbiotic partner, shortening the breeding cycle, rapid seed viability test, obtaining rare hybrids and homozygous lines, and haploid production (Bhojwani and Razdan, 1996; Gürel et al., 1991; Raghavan, 2003; Saji and Sujatha, 1998; Torresàn et al., 1996; Yeung et al., 1998; Zhong et al., 1995). By using embryo culture, the breeding cycles of sunflower (Jambhulkar, 1995; Torresàn et al., 1996), artichoke (Cravero and Cointry, 2007), wheat (Sharma and Gill, 1982), soybean (Roumet and Morin, 1997), orchids, roses and bananas (Yeung et al., 1981), iris (Randolph, 1945), and azalea (Michishita et al., 2001) have been shortened from one to three years to a few months depending on the plant. Jambhulkar (1995) has developed a rapid embryo-raised plant system for sunflower production from immature embryos, which allows five cycles in 
316 days. The purpose of the present study was to develop plants under sterile conditions from immature embryos grown in in vitro culture. A technique has been developed that can be applied to propagate $\mathrm{N}, \mathrm{R}$ and $\mathrm{cms}$ lines by speeding up the breeding process in hybrid seed production.

\section{MATERIALS AND METHODS}

Five sunflower (Helianthus annuus L.) maintainers (N Record 109/Sanay 1-2, BGC0565, N Record 109/Iscra, RIM 1-3, Malkara Çerez/P4313), five restorers (RHA 04, RHA 06, RHA 10, RHA 14, RHA 15), and five cms lines (PR6404, Narmo Sanay 6-1, N Record 109/Sanay 1-2, RIM 1-5, Malkara Çerez/P4313) were grown under field conditions at Uludag University, Agricultural Research and Experiment Station in 2009. These genotypes were selected from the collection of Uludag University, Field Crops Department because of their early flowering and maturity. The plants were hand-pollinated and maintained until the seeds were mature. Ten to 12 days after pollination the heads were brought into the laboratory. The achenes from the outer 3-4 rows of the inflorescence were separated. To homogenize the embryos, achenes with dark color had been selected. The embryos with pericarps were sterilized with $20 \%$ commercial bleach with a few drops of detergent for 10 minutes. They were then rinsed three times with sterile distilled water. The immature embryos were excised from the pericarps, endosperm and embryo sac in order to produce the first cycle of plants. They were then placed onto the Murashige and Skoog (1962) medium with $2 \%$ sucrose and 0.8\% agar at pH 5.6-5.7 as described by Jambhulkar (1995). All studies were carried out under sterile conditions. The Petri dishes, sealed with Parafilm to prevent moisture loss, were placed in the light ( $16 \mathrm{~h} / 8 \mathrm{~h}$ day / night) at $25 \pm 2^{\circ} \mathrm{C}$ and cultured for 4 weeks to form plantlets. Within two weeks of culture on MS, the developing embryos grew plantlets with strong roots $(2-6 \mathrm{~cm}$ and branching) and a stem $(3-5 \mathrm{~cm})$ with $6-8$ leaves $(1 \mathrm{~cm})$. Plantlets washed agar debris were then placed in 31 by $51 \mathrm{~cm}$ plastic multipot trays of 48 pots per tray containing a sterile 1:1:2 peat:perlite:soil mixture $(\mathrm{v}: \mathrm{v})$. The trays were covered with a plastic bag and incubated for a period of 7-10 days in the growth chamber at $25 \pm 2^{\circ} \mathrm{C}$ in the light $(16 \mathrm{~h} / 8 \mathrm{~h}$ day / night), after which the plantlets were transferred to $320 \times 2.70 \mathrm{~mm}$ ( $16 \mathrm{lt}$ ) pots with regular soil, keeping 2-3 plants per pot in the same growth chamber. The plantlets were irrigated with sterile water three times a week in order to maintain a high humidity environment and fertilized every 10 days. Plantlets had flowers eight weeks after sowing and set seed. The number of plantlets regenerated and mature plants obtained was recorded. Developed seeds and empty seeds per head were counted. Some seeds from some of the regenerants were planted and germinated to produce sunflower plants. Thus, the $2^{\text {nd }}$ cycle of ERP was obtained. Each genotype was represented with 10-15 Petri dishes $(9 \mathrm{~cm})$ with 10 embryos in each. Observations were made of the efficiency of immature embryos (EIE) (\%), embryos developing plantlets, growth of shoots and 
roots as score and intensity (\%), and mean leaf number per explant (number) at the Petri dish stage. EIE was calculated through the rate number of plants obtained/ number of immature embryo excised. Shoot and root development on the plantlet was scored as described in Table 1. Rooting and shooting score data were rated from 0 to 4 . A number of growth traits (head production, $50 \%$ of flowering dates, pollination dates, embryo emasculation dates, transferred to soil dates) and agronomic traits (plant height, head diameter, plant width, leaf number, number of branches, number of filled seeds per head) were determined for each of the individual plants in the pots.

Table 1: Rooting and shooting score rating scale

\begin{tabular}{ll}
\hline Key & Description \\
\hline 0 & No roots or shoots \\
1 & Roots with up to1 $\mathrm{cm}$ average length and shoots with up to $3 \mathrm{~cm}$ average length \\
2 & Roots and shoots with $3-5 \mathrm{~cm}$ average length \\
3 & Roots and shoots bigger than $5 \mathrm{~cm}$ average length \\
\hline
\end{tabular}

\section{RESULTS AND DISCUSSIONS}

The first cycle of regeneration procedure was developed from immature embryos from field grown plants. Immature seeds removed as early as 10 days after pollination were successfully cultured in vitro. If the excised embryos were able to grow, most had a shoot and a root after a week. Out of the 1,710 immature embryos, the average response of the explants was 93.1\% (1591), showing morphogenesis with a minimum of 42.5 [N Record 109/Sanay 1-2(N)] and a maximum of 100\% [(PR6404 (cms), Narmo Sanay 6-1 (cms), RIM 1-5 (cms), BGC0565 (N), N Record 109/Iscra (N), RHA 04, RHA 06, RHA 10, RHA 14, RHA 15]. The regeneration response of immature embryos was scored after 3 weeks, evaluating the growth of the shoots and roots and its intensity. Within four weeks of culture on MS (Jambhulkar, 1995), the developing embryos mainly grew plantlets with strong roots (2$6 \mathrm{~cm}$ and branching) and a stem with 6-8 leaves $(1 \mathrm{~cm})$. The majority of the cultured embryos developed into plantlets in accordance with Jeannin and Hahne (1991). Seventy percent of the developed plantlets had vigorous roots. Plantlets were then transferred aseptically and without injury to plastic multipot trays for two weeks in a growth chamber. Although all of the cultured genotypes were grown in the MS medium during the first stage and were then transferred into the peat:perlite:soil mixture, 33\% of them acclimatized (data not shown). RHA 10, RIM 1-3, N Record 109/Sanay 1-2, RIM 1-5, and PR6404 (33\%) managed to produce mature plants in the growth chamber. Of the embryos that developed, $14.2 \%$ were in the peat:perlite:soil mixture and only $67.5 \%$ of them were grown to maturity, either self-pollinated or pollinated with maintainers and set seeds (Table 2). Plantlets bloomed 4-6 weeks later and set seed. Then, after two-three weeks of in vitro culture and about 15 days of acclimatization, the plantlets were transferred to the 
pots at least four-five months earlier than would normally be possible, thus reducing seed-to-seed cycle.

Approximately 80 (14.2\% of the immature embryos plated) primary plantlets were regenerated and moved to trays. Only about $67.5 \%$ of the transferred primary plantlets matured, self pollinated, and set seeds. This study reports the results of improvement in growing sunflower plants from in vitro immature embryo in the growth chamber. The plants were evaluated for their growth.

Table 3 shows a number of growth and agronomic performances of $1^{\text {st }}$ generation plants obtained in vitro. There were no big morphological changes in the regenerated plants. In our study, rapid-cycling genotypes of sunflower were selected and completed their life cycles in about 106-112 days in field conditions, as compared to the 150-160 days of late flowering genotypes. In general, days to flowering of seed grown plants obtained in vitro ranged from 61 to 70 days and days to harvest of those plants ranged from 106 to 112 days, indicating the minimum need of 106 days for RIM 1-5 and 112 days for RHA 10 for completing regeneration in a year. However, the minimum requirement for completing the seed to seed cycle was 86 days when using the dwarf and early maturing genotype Morden. The $1^{\text {st }}$ cycle of embryo raised plants was completed after 65 days by using the same genotype. Consequently, both immature embryo culture and selection of rapid-cycling lines of sunflower produced five generations per year (Jambhulkar, 1995).

Table 2: Estimation of efficiency of the regeneration procedure

\begin{tabular}{|c|c|c|c|c|c|c|c|c|c|}
\hline \multirow[t]{2}{*}{ Genotypes } & \multirow{2}{*}{$\begin{array}{c}\begin{array}{c}\text { Immature } \\
\text { embryos } \\
\text { plated }\end{array} \\
\text { No }\end{array}$} & \multicolumn{2}{|c|}{$\begin{array}{l}\text { Plantlets transferred } \\
\text { to peat:perlite:soil }\end{array}$} & \multicolumn{3}{|c|}{$\begin{array}{l}\text { Mature plants } \\
\text { obtained }\end{array}$} & \multicolumn{3}{|c|}{ Seed number per head } \\
\hline & & No & $\%$ & $\mathrm{EIE}^{\mathrm{a}}$ & No & $\%$ & Empty & Developed & Total \\
\hline RHA $10(\mathrm{R})$ & 127 & 25 & 19.7 & 14.2 & 18 & 72.0 & 487 & 283 & 770 \\
\hline RIM 1-3 (N) & 121 & 5 & 4.1 & 1.7 & 2 & 40.0 & 40 & 120 & 160 \\
\hline $\begin{array}{l}\text { N Record 109/ } \\
\text { Sanay 1-2 (cms) }\end{array}$ & 114 & 22 & 19.3 & 16.7 & 19 & 86.4 & 275 & 231 & 506 \\
\hline RIM 1-5 (cms) & 80 & 27 & 33.8 & 17.5 & 14 & 51.9 & 513 & 183 & 696 \\
\hline PR6404 & 121 & 1 & 0.8 & 0.8 & 1 & 100 & 101 & 174 & 275 \\
\hline Total & 563 & 80 & 14.2 & 9.6 & 54 & 67.5 & 1416 & 991 & 2407 \\
\hline
\end{tabular}

$\mathrm{EIE}^{\mathrm{a}}=$ Efficiency of the immature embryo: the number of mature plants obtained/total number of immature embryos excised

The regenerated plantlets showed variations for plant height, head diameter, number of branches, plant width, number of leaves, and seed number per head. In general, plant height, plant width, seed number per head, and head diameter decreased when the in vitro technique was used. Of the genotypes used, PR6404 had the tallest plants $(83 \mathrm{~cm})$ and N Record 109/ Sanay the shortest $(19.7 \mathrm{~cm})$. All the plants transferred to soil produced flowers that contained both fertile and sterile seeds. When the plants were harvested, all the heads produced seeds ranging in number from 160 to 770 in total according to genotype. Similarly, Gopalkrishnan 
et al. (1993) observed that the vegetative phase of embryo derived plants was very short, resulting in small plants $(12-25 \mathrm{~cm})$, flower buds and early flowering compared to plants grown in field conditions. Our results indicate that it is possible to produce viable seeds from plants grown in vitro and to obtain three generations a year.

The plant height of individual sunflower plants obtained from in vitro culture varied between 20 and $50 \mathrm{~cm}$, as reported earlier by Hahne (2002). The size of the individual flowers ranged from a few ray flowers surrounding a small number of disk flowers to sunflower heads of reasonable size with more than 150 seeds in this study. The regenerated plants had a minimum of three and a maximum 16 small green leaves at harvesting. The development time from collecting immature embryos to harvesting seeds takes 4-5 months in our culture system.

Table 3: A number of growth and agronomic performances of $1^{\text {st }}$ generation plants obtained from in vitro

\begin{tabular}{|c|c|c|c|c|c|c|c|c|c|c|c|c|}
\hline \multirow[t]{2}{*}{ Genotypes } & \multirow{2}{*}{$\begin{array}{c}\text { Days } \\
\text { to flo- } \\
\text { wering }\end{array}$} & \multirow{2}{*}{$\begin{array}{c}\text { Days } \\
\text { to har- } \\
\text { vest }\end{array}$} & \multicolumn{2}{|c|}{$\begin{array}{l}\text { Plant height } \\
\text { (cm) }\end{array}$} & \multicolumn{2}{|c|}{$\begin{array}{l}\text { Head diameter } \\
\text { (cm) }\end{array}$} & \multicolumn{2}{|c|}{$\begin{array}{l}\text { Number of } \\
\text { branches }\end{array}$} & \multicolumn{2}{|c|}{$\begin{array}{l}\text { Plant width } \\
(\mathrm{mm})\end{array}$} & \multicolumn{2}{|c|}{$\begin{array}{l}\text { Number of } \\
\text { leaves }\end{array}$} \\
\hline & & & $\overline{\text { Mean }}$ & Range & Mean & Range & Mean & Range & Mean & Rang & Mean & Range \\
\hline $\mathrm{RHA}$ & 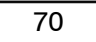 & 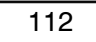 & 26.1 & $11-50$ & 2.5 & $1.5-6$ & 1.7 & $0-6$ & 4.3 & $2.5-6$ & 9.6 & $6-13$ \\
\hline $\begin{array}{l}\text { NRe } \\
\text { Sane }\end{array}$ & 6 & 109 & 19 & $5-42$ & 2.3 & 1 & 0. & $0-6$ & 3.8 & 6.5 & 7.9 & 3-12 \\
\hline RIN & 6 & 106 & 33.4 & $6-62$ & 3.2 & 5 & 1.4 & 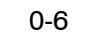 & 5.1 & $4-6$ & 11.1 & $5-16$ \\
\hline PR & 68 & 109 & 83 & 83 & 5.5 & 5.5 & 1.0 & 1.0 & 5.8 & 5.8 & 24 & 24 \\
\hline RIM1-3 & 65 & 109 & 22.3 & $10-35$ & 2.8 & $2-3.5$ & 4.5 & $2-7$ & 3.5 & $2-3.5$ & 9.5 & $8-11$ \\
\hline
\end{tabular}

The overall result was an average of 54 regenerated and matured plants per 563 excised immature embryos. Although the agronomic characters of in vitro regenerated plants decreased, more than 150 seeds were harvested for each genotype and at least 120 of them were viable and developed. This was sufficient for continuing on to the next generation. This method will be useful for breeders in the advancement of sunflower breeding. The three generations a year advanced the breeding of the genetic population. Therefore, homozygosity will be developed in two years if the population is derived from a cross between two inbred lines. In the future we are planning to improve this technique to make it possible to obtain at least 4-5 generations in a year.

It is also known that when the mature seeds of most sunflower lines are freshly harvested, they do not germinate due to dormancy. By using immature embryo culture, the dormancy problem can be solved easily. This technique will shorten the breeding cycle for sunflower, permitting the production of plantlets almost one third of a year earlier than when seeds grown in natural conditions in the field are used. In conclusion, embryo culture techniques avoid embryo abortion and seed dormancy. This technique can be useful in breeding schemes where small numbers of plants are needed per generation. 


\section{REFERENCES}

Bhojwani, S.S. and Razdan, M.K., 1996. Zygotic Embryo Culture, Chapter 11. In: Plant Tissue Culture: Theory and Practice, A Revised Edition. Elsevier, Science B.V. The Netherlands, pp. 297-335.

Chandler, J.M. and Beard, B.H., 1983. Embryo culture of Helianthus hybrids. Crop Sci. 23: 1004-1007.

Cravero, V. and Cointry, E., 2007. Short communication. Shortening the seed-to-seed cycle in artichoke breeding by embryo culture. Plant Breeding 126: 222-224.

Gopalkrishnan, K., Naidu, M.R. and Sreedhar, D., 1993. Shortening breeding cycle through immature embryo culture in sunflower (Helianthus annuus L.). Helia 16: 61-68.

Gürel, A., Nichterlein, K., Friedt, W., 1991. Shoot regeneration from anther culture of sunflower (Helianthus annuus) and some interspecific hybrids as affected by genotype and culture procedure. Plant Breeding 106: 68-76

Hahne, G., 2002. Sunflower seed (Chapter 54). In: Khachatourians, G.G., McHughen, A., Scorza, R., Nip, W-K. and Hui, Y. H. (Eds.), Transgenic Plants and Crops. pp. 813-830.

Hu, J., Yue, B., Yuan, W., and Vick, B.A., 2008. Growing sunflower plants from seed to seed in small pots in greenhouse. Helia 31(48): 119-126.

Maiti, R.K., Vidyasagar, P., Shahapur, S.C., Ghosh, S.K., Seiler, G.J., 2006. Development and standardization of a simple technique for breaking seed dormancy in sunflower (Helianthus annuus L.). Helia 29(45): 117-126.

Michishita, A., Ureshino, K. and Miyajima, I., 2001. Shortening the period from crossing to the seedling stage through ovule culture of interspecific crosses of azelea (Rhododendron spp.). J. Japan. Soc. Hort. Sci. 70(1): 54-59.

Murashige, T. and Skoog, F., 1962. A revised medium for rapid growth and bioassays with tobacco tissue cultures. Physiol Plant. 15(3): 473-497.

Raghavan, V., 2003. One hundred years of zygotic embryo culture investigations. In vitro Cell. Dev. Biol. Plant. 39: 437-442.

Randolph, L.F., 1945. Embryo culture of Iris seeds. Bulletin of the American Iris Society 97: 33-45.

Roumet, P. and Morin, F., 1997. Germination of immature soybean seeds to shorten reproductive cycle duration. Crop Science 37: 521-525.

Saji, K.V. and Sujatha, M., 1998. Embryogenesis and plant regeneration in anther culture of sunflower (Helianthus annuus L.). Euphytica 103(1): 1-7.

Serieys, H., 1992. Cytoplasmic effects on some agronomical characters in sunflower. Proc. of the $13^{\text {th }}$ Int. Sunflower Conf., Pisa, Italy, September 7-11. 2: 1245-1250.

Sharma, H.C. and Gill, B.S., 1982. Effect of embryo age and culture media on plant growth and vernalization response in winter wheat. Euphytica 31: 629-634.

Yeung, E.C., Thorpe, T.A. and Jensen, C.I., 1981. In vitro fertilization and embryo rescue. In: Thorpe, T.A. (Ed.) Plant Tissue Culture: Methods and Applications in Agriculture, Academic Press, New York. pp. 253-271.

Zhong, D., Michaux-Ferriere, N. and Coumans, M., 1995. Assay for doubled haploid sunflower (Helianthus annuus) plant production by androgenesis: fact or artifact? Part 1. In vitro anther culture. Plant Cell, Tissue and Organ Culture 41: 91-97. 
